\title{
The adenovirus E1A proteins induce apoptosis, which is inhibited by the E1B 19-kDa and Bcl-2 proteins
}

\author{
Lakshmi Rao*, Michael Debbas*, Peter Sabbatini* ${ }^{*}$, David Hockenbery $\ddagger$, Stanley Korsmeyer $\ddagger$, \\ AND EILEEN WHITE*†§ \\ ${ }^{*}$ Center for Advanced Biotechnology and Medicine, and Department of Biological Sciences, Rutgers University, 679 Hoes Lane, Piscataway, NJ 08854 ; ${ }^{\dagger}$ Cold \\ Spring Harbor Laboratory, Cold Spring Harbor, NY 11724; and ‡Howard Hughes Medical Institute, Washington University School of Medicine, 660 South \\ Euclid Avenue, Saint Louis, MO 63110
}

Communicated by Aaron J. Shatkin, May 20, 1992 (received for review April 9, 1992)

\begin{abstract}
Cooperation between the adenovirus E1A and E1B oncogenes is required for transformation of primary quiescent rodent cells. Although expression of E1A alone will stimulate cell proliferation sufiicient to initiate transformed focus formation, proliferation fails to be sustained and foci degenerate. Coexpression of either the 19-kDa or 55-kDa E1B oncoproteins with E1A permits high-frequency transformation by overcoming this cytotoxic response. Without E1B 19-kDa protein expression, however, transformants remain susceptible to induction of cell death. Rapid loss of viability is coincident with nucleolytic cleavage of DNA in intranucleosomal regions and chromatin condensation, hallmarks of programed cell death (apoptosis). Furthermore, overexpression of a known suppressor of apoptosis, the Bcl-2 protooncogene, can rescue E1Ainduced focus degeneration. Thus E1A-dependent stimulation of cell proliferation is accompanied by apoptosis and thereby insufificient to singly induce transformation. High-frequency transformation requires a second function encoded by the E1B 19-kDa protein to block apoptosis.
\end{abstract}

The adenovirus E1A proteins play an essential role in productive viral infection and cooperate with the products of the E1B oncogene to promote the oncogenic transformation of primary rodent cells (1). The E1B gene encodes two distinct tumor antigens, the $19-\mathrm{kDa}$ and $55-\mathrm{kDa}$ proteins, which are both independently capable of promoting transformation in cooperation with E1A (2-5). The function of the E1B 55-kDa protein in transformation likely derives from a physical association with the $\mathrm{p} 53$ tumor suppressor gene product (6), whereas the function of the E1B 19-kDa protein in transformation has been unclear. In productively infected cells, however, the E1B 19-kDa protein has a well-established function in blocking DNA fragmentation (7-10) and premature death of the host cell $(11,12)$ induced by expression of the E1A proteins (13-15). These cytotoxic effects of E1A resemble induction of programed cell death or apoptosis and suggested that the function of the E1B 19-kDa protein may be inhibition of apoptosis (14).

In support of this idea, the E1B 19-kDa protein was found to be a potent inhibitor of the cytotoxic action of tumor necrosis factor $\alpha$ (TNF- $\alpha$ ) or anti-Fas antibodies (16-18), both of which induce apoptosis $(19,20)$. In the case of TNF- $\alpha$, the ability of the E1B $19-\mathrm{kDa}$ protein to block DNA fragmentation and death was genetically inseparable from transforming activity (18). The single event of suppressing apoptosis may therefore account for TNF- $\alpha$ resistance and transforming activity of the E1B 19-kDa protein. We have examined the role of E1A and E1B in transformation of primary rodent cells and found that E1A expression elicits a cytotoxic response that resembles apoptosis. Coexpression

The publication costs of this article were defrayed in part by page charge payment. This article must therefore be hereby marked "advertisement" in accordance with 18 U.S.C. $\$ 1734$ solely to indicate this fact. of E1B, predominantly the $19-\mathrm{kDa}$ protein, or the human Bcl-2 protooncogene with E1A mitigates the cytotoxic response and rescues transformation.

\section{MATERIALS AND METHODS}

Primary Cell Transformation Assays. Kidneys were excised from 6-day-old Fischer rats (Taconic Farms), treated with collagenase and dispase to produce a uniform cell suspension, and transfected by electroporation as described (14). Plasmid DNAs were linearized by restriction enzyme digestion and $20 \mu \mathrm{g}$ of total DNA (10-15 $\mu \mathrm{g}$ of each plasmid with the remainder made up with denatured salmon sperm DNA) per kidney was transfected. Transfected cells were then plated in Dulbecco modified Eagle medium (DMEM) with $5 \%$ fetal bovine serum and changed weekly. Plates were fixed with methanol/acetone (1:1) for $15 \mathrm{~min}$ and stained with $20 \%$ Giemsa in phosphate-buffered saline (PBS) for $20 \mathrm{~min}$.

Viability Assays. Previously described transformed cell lines (2) at low passage were plated at low density $\left(1 \times 10^{5}\right.$ cells per dish) in multiple $2.5-\mathrm{cm}$ dishes in DMEM with $10 \%$ fetal bovine serum. Once daily up to 12 days after plating the cells were trypsinized and the viable cell number per plate was determined by staining with Trypan blue.

DNA Fragmentation Assays. Transformed baby rat kidney (BRK) cell lines were plated in $10-\mathrm{cm}$ dishes and treated essentially as described for viability assays. The culture medium from all nine transformed BRK cell lines containing most of the floating, predominantly dead cells was harvested by low-speed centrifugation. Low molecular weight DNA was extracted from the cell lines by the method of Hirt (21) with minor modifications (7). Equal volumes of Hirt supernatant fractions from BRK lines were analyzed by electrophoresis in a $1 \%$ agarose gel and visualized by ethidium bromide staining. Ad5dl309 (22) DNA digested with HindIII was used as molecular weight markers.

Ultrastructural Analysis. For electron microscopy the 55C cell line was maintained in high or low serum for $24 \mathrm{hr}$ as described above and $\approx 5 \times 10^{5}$ cells were harvested, washed in PBS, pelleted, and fixed in $2.5 \%$ glutaraldehyde in $0.1 \mathrm{M}$ sodium cacodylate buffer ( $\mathrm{pH} 7.3$ ) overnight, followed by postfixation with buffered $1 \%$ osmium tetroxide ( $\mathrm{pH} 7.3$ ) for $1 \mathrm{hr}$. Samples were embedded in Econ 812, sectioned, and stained for $20 \mathrm{~min}$ in $2 \%$ aqueous uranyl acetate and for $2 \mathrm{~min}$ in lead citrate. Grids were viewed on a JOEL $200 \mathrm{EX}$ electron microscope.

Antibodies and Western Blotting. Cell extracts were prepared from transformed BRK cell lines and Western blotting was performed by standard procedures. Immune complexes were visualized by the enhanced chemiluminescence method

Abbreviations: BRK, baby rat kidney; TNF- $\alpha$, tumor necrosis factor $\alpha$. $\S$ To whom reprint requests should be addressed. 
(Amersham). The monoclonal antibody directed against human Bcl-2, 6C8, was previously described (23). Monoclonal antibody $\mathrm{Bcl}-2 / 100$ directed against human $\mathrm{Bcl}-2$ was generously provided by David Mason (John Radcliffe Hospital, Oxford, U.K.).

\section{RESULTS}

E1A Expression Is Sufficient for Initiation of Focus Formation. Primary BRK cell cultures prepared from 6-day-old Fischer rats were used as a source of normal cells with which to examine the transforming activity of the adenovirus E1A and E1B gene-encoded proteins. These cells are quiescent and display no significant levels of spontaneous transformation (Fig. 1). Plasmids encoding E1A under the direction of the E1A promoter ( $\mathrm{pE} 1 \mathrm{~A})$ and a series of E1B expression vectors designed to express the 19-kDa protein (pCMV19K), the 55-kDa protein (pCMV55K), or an intact E1B gene (pCMVE1B) $(2,24)$ were introduced and focus development was monitored over time. In the initial 14 days, there was surprisingly little difference in the number of foci obtained between transfection of the E1A gene alone or in conjunction with E1B gene (Fig. 1). As the E1B gene has no detectable focus-forming ability in the absence of $\operatorname{E1A}(14,25), \mathrm{E} 1 \mathrm{~A}$ can induce focus formation in an efficient manner that is independent of E1B. However, the E1A-induced foci fail to grow significantly in the following 2-week period. Eventually, $<15 \%$ of these will give rise to E1A immortalized clones at 5-6 weeks after transfection (18).

Expression of Either E1B Protein Is Required for Sustained Growth of Transformed Foci. At 2-4 weeks after transfection, when E1A-derived foci fail to progress, the requirement for E1B gene expression in transformation becomes strikingly apparent. Coexpression of the E1B $19-\mathrm{kDa}$ protein or an intact E1B gene with E1A dramatically enhances the proliferative capacity of the transformants and $>75 \%$ that form initially are capable of sustaining growth (Fig. 1). Coexpression of the E1B 55-kDa protein also facilitates continued expansion but to a lesser extent than the E1B 19-kDa protein (Fig. 1). Therefore, oncogenic transformation can be divided

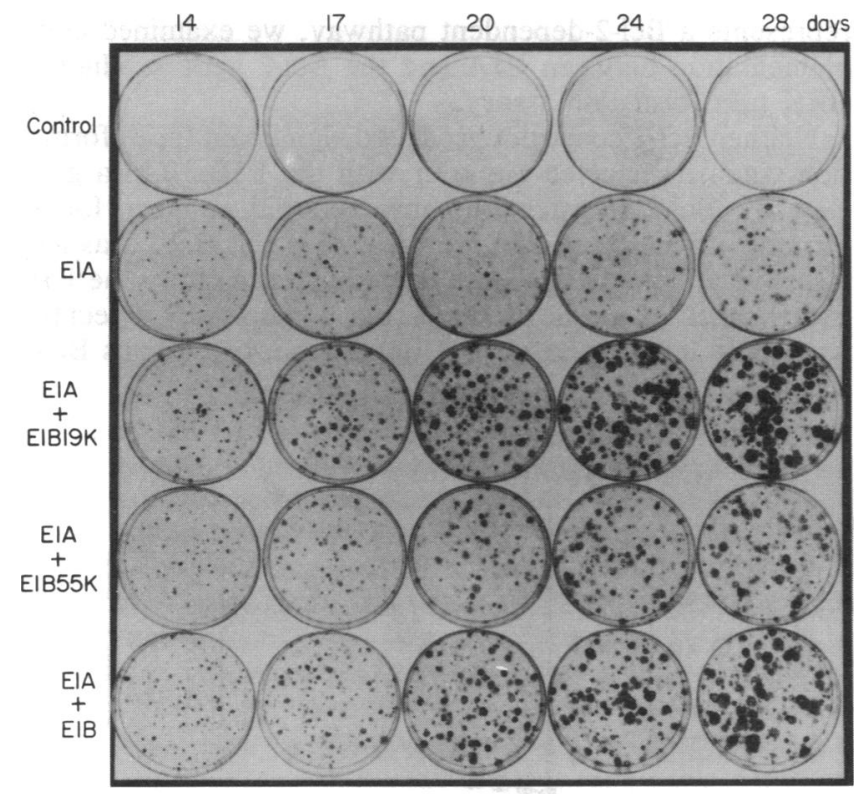

Fig. 1. Rescue of E1A-induced focus formation by E1B. Primary BRK cells were transfected plasmids encoding E1A ( $\mathrm{pE1A}$ ) or E1B expression vectors that express exclusively the E1B 19-kDa (E1B19K) protein (pCMV19K), the E1B 55-kDa (E1B55K) protein (pCMV55K), or an intact E1B gene (pCMVE1B) $(2,24)$. At the indicated times the plates were fixed and stained with Giemsa to reveal foci (14). into two distinct phases, distinguished temporally and by the differential requirements for E1A and E1B gene expression. The first phase represents induction of cell proliferation and initiation of focus formation, which is exclusively E1A dependent and E1B independent. The second subsequent phase required to sustain proliferation is E1B dependent.

E1A Induces Focus Degeneration in the Absence of E1B. E1A expression is sufficient to promote the $G_{0}$ or $G_{1}$ to $S$ transition and stimulate cellular DNA synthesis in quiescent cells $(26,27)$. The ability of E1A to efficiently initiate proliferation and focus formation is consistent with these observations. However, the failure of E1A to subsequently sustain proliferation and the requirement for E1B gene products for this function suggested that E1B functioned downstream of E1A. When E1A-induced foci were examined microscopically during the E1B-dependent phase of transformation, it was apparent that the absence of continued transformed focus progression was due to induction of significant levels of cell death (Fig. 2). Large numbers of highly refractile, nonviable cells (determined by an inability to exclude trypan blue) were observed associated with foci derived from transfection of E1A alone, and foci underwent degeneration (Fig. 2). Coexpression of E1A with the E1B 19-kDa protein, either in the context of an intact E1B gene or the pCMV19K expression vector, abrogated all signs of cell death, whereas coexpression of the $\mathrm{E} 1 \mathrm{~B} 55-\mathrm{kDa}$ protein was less effective (Fig. 2). This indicated that the E1B 19-kDa protein may be increasing the proliferative capacity of E1A transformants by inhibiting cell death, perhaps by apoptosis. The possibility that the differential suppression of cell death by the E1B 19-kDa and 55-kDa proteins during focus formation may be reflected in the growth characteristics of transformed BRK cell lines was investigated.

Transformed Cell Lines That Do Not Express the E1B 19-kDa Protein Are Susceptible to Cell Death. A series of independently derived stable cell lines have been produced from transfection of BRK cells with $E 1 A$ and $E 1 B$ expression vectors that differentially express the E1B proteins (2). These lines possess many characteristics of transformed cells and express comparable levels of E1A proteins. However, they differentially responded to growth to high-saturation density or serum deprivation, conditions known to induce apoptosis in other cell types (reviewed in ref. 28). Induction of cell death in the different transformed cell lines upon growth from low to high density was monitored in a viability assay (Fig. 3). Cell lines that expressed the E1B 19-kDa protein (either $\mathrm{E} 1 \mathrm{~A}+\mathrm{E} 1 \mathrm{~B}$ or E1A+E1B 19-kDa transformants) maintained viability for at least 3 days after reaching saturation density (Fig. 3). In contrast, E1A + E1B 55-kDa transformants demonstrated a pronounced and rapid loss of viability immediately after achieving saturation density (Fig. 3).

Expression of the E1B 19-kDa Protein Prevents Cell Death by Apoptosis. Cell death can occur nonspecifically by necrosis, which involves loss of membrane integrity and lysis, or by a specific process called apoptosis or programed cell death (29). Features that distinguish apoptosis from necrosis are the induction of nuclear DNA fragmentation in intranucleosomal regions and chromatin condensation. By using these criteria, dying E1A +E1B 55-kDa transformed cell lines were examined for induction of apoptosis. All nine transformed cell lines were plated at low density and 3 days after reaching saturation density, when the differential viability of the cell lines was maximal $(<50 \%$ in $\mathrm{E} 1 \mathrm{~A}+\mathrm{E} 1 \mathrm{~B} 55-\mathrm{kDa}$ lines and $>95 \%$ in $\mathrm{E} 1 \mathrm{~A}+\mathrm{E} 1 \mathrm{~B}$ and E1A + E1B 19-kDa lines), degraded DNA was isolated by the method of Hirt (21). This procedure permits the quantitative recovery of low molecular weight DNA, either degraded or viral DNA, for example, from high molecular weight chromosomal DNA. DNA fragmentation with a characteristic "ladder" pattern indicative of intranucleosomal cleavage events occurred in dead cells from all three 

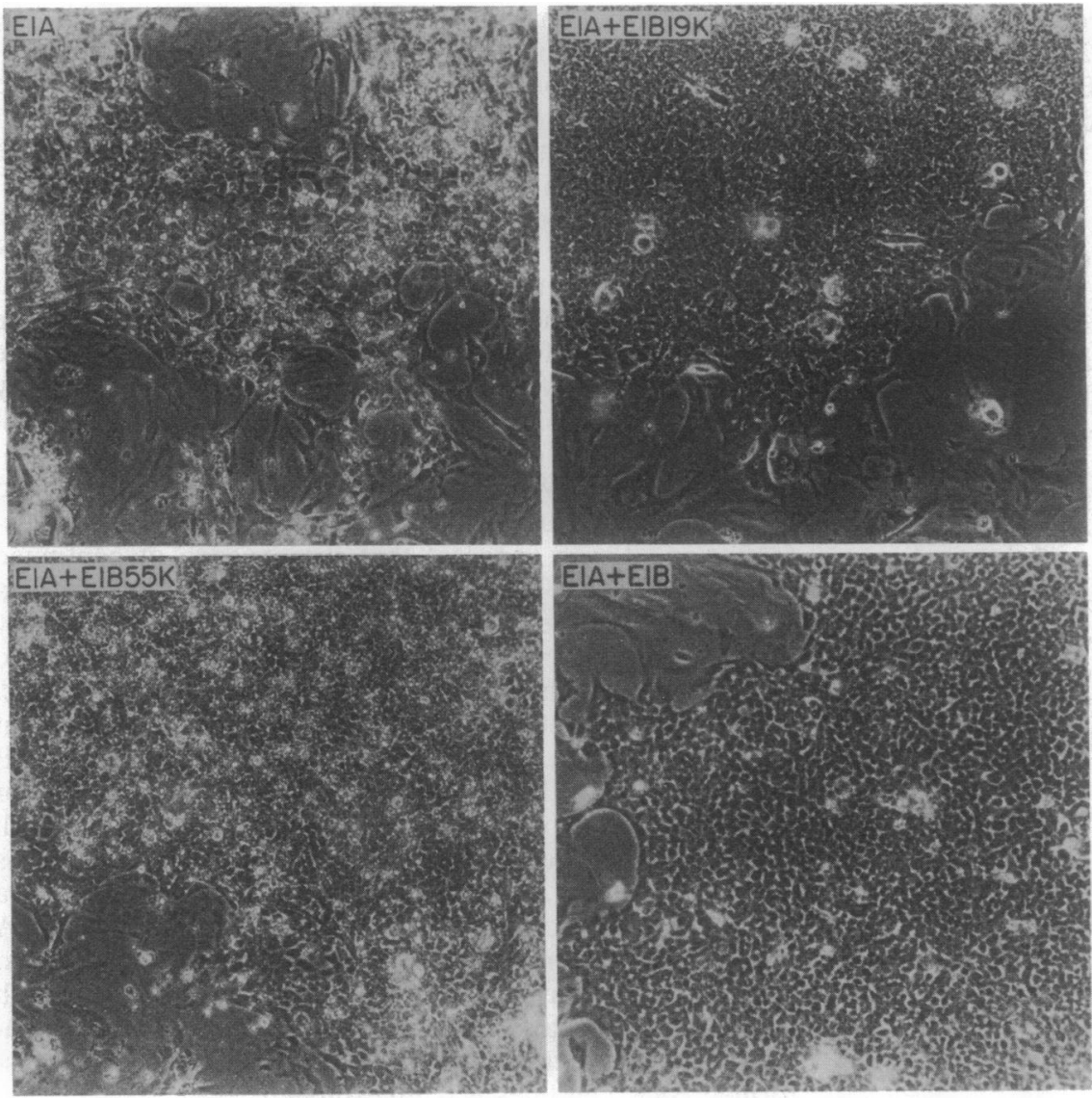

Fig. 2. Transformed focus degeneration in the absence of E1B 19-kDa gene expression. Foci from a BRK transformation experiment as described in the legend to Fig. 1 were photographed with a Nikon inverted-phase microscope in the third week following electroporation. $(\times 25$.
E1A+E1B 55-kDa cell lines (Fig. 4 Upper). No low molecular weight DNA was detectable in identically treated cell lines that expressed the E1B 19-kDa protein (Fig. 4 Upper).

One of the E1A+E1B 55-kDa cell lines (55C) was examined at the ultrastructural level for a morphological indication of apoptosis, chromatin condensation. In normal concentrations of fetal bovine serum (10\%), where viability was high, cells appeared ultrastructurally normal (Fig. 4 Lower Left) and not substantially different from E1A + E1B transformants (data not shown). Under conditions of serum deprivation ( $0.1 \%$ for $24 \mathrm{hr}$ ), where viability was low, cells frequently possessed large masses of condensed chromatin (Fig. 4 Lower Right). Thus, expression of the E1B 19-kDa protein during oncogenic transformation is required to suppress the induction of apoptosis.

Cooperation Between E1A and Bcl-2. The Bcl-2 protooncogene was identified at a site of chromosomal translocation in human B-cell lymphoma (30-32). Its overexpression in certain hematopoietic cell lines results in the suppression of apoptosis $(23,33,34)$. Moreover, transgenic mice bearing a Bcl-2-Ig minigene progress to monoclonal lymphoma (35). However, although Bcl-2 is highly effective in blocking many apoptotic pathways, others have been noted to be independent $(34,36)$. To determine whether E1A-related apoptosis represents a Bcl-2-dependent pathway, we examined complementation between E1A and the Bcl-2 gene product in BRK transformation assays.

Neither Bcl-2 construct produced significant focus formation when transfected alone or with the E1B 19-kDa gene (Fig. 5). Bcl-2 transfection, however, did enhance focusforming efficiency of E1A by 4-fold (Fig. 5). Bcl-2 was less effective at stimulating focus formation than either the E1B $19-\mathrm{kDa}$ or 55-kDa gene products (Fig. 5). This may reflect the use of the human and not rat $\mathrm{Bcl}-2$ gene, or perhaps $\mathrm{Bcl}-2$
E1A+E1B 55K

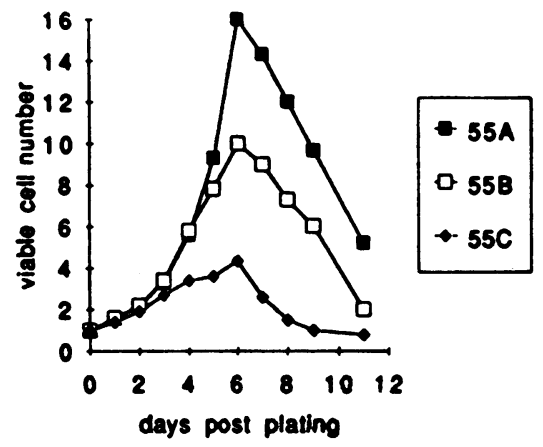

E1A+E1B

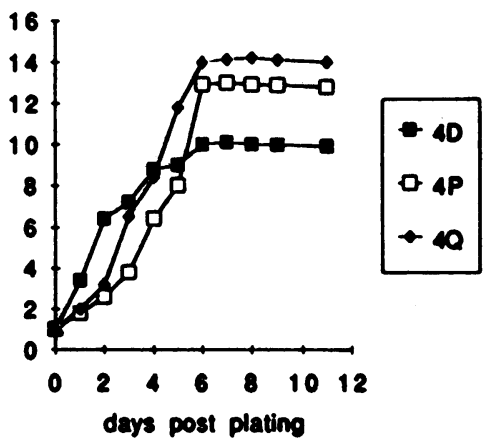

E1A+E1B 19K

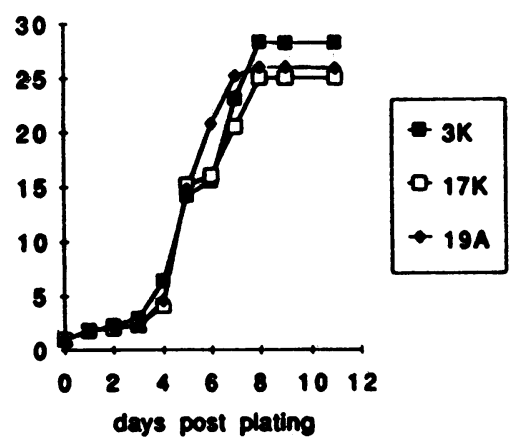

FIG. 3. Expression of the E1B 19-kDa protein is required to maintain transformed cell viability at high cell density. Independent, stable, transformed BRK cell lines expressing E1A+E1B 55-kDa (Left), E1A+E1B (Center), and E1A+E1B 19-kDa (Right) proteins (2) were monitored for viability by trypan blue exclusion over time. Actual viable cell numbers are plotted $\left(\times 10^{-5}\right)$ versus days post plating. 


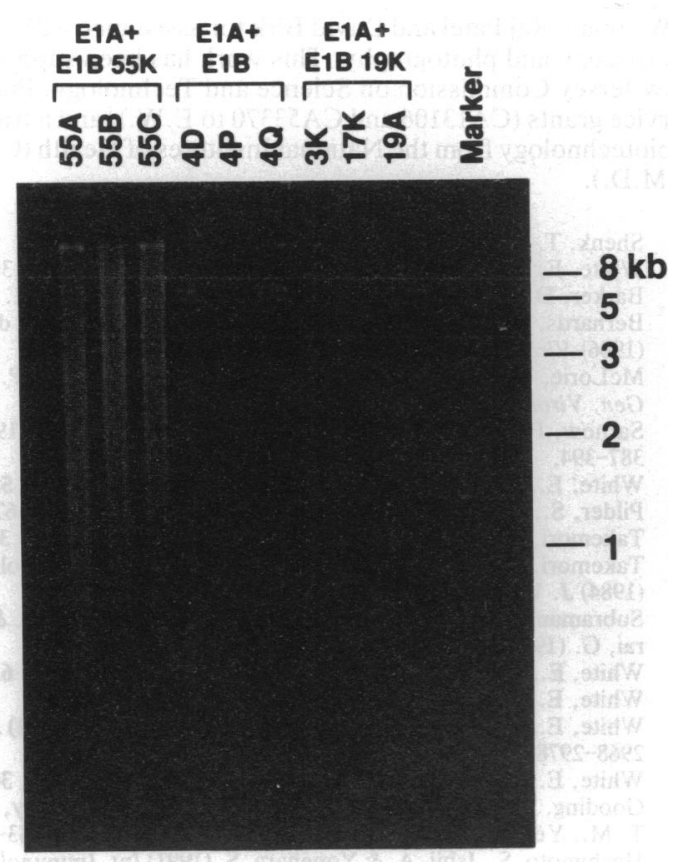

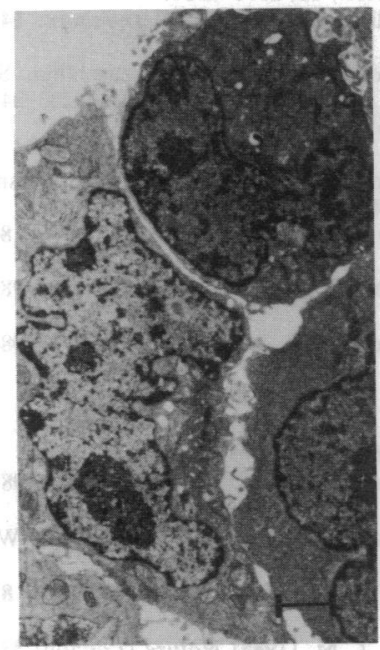

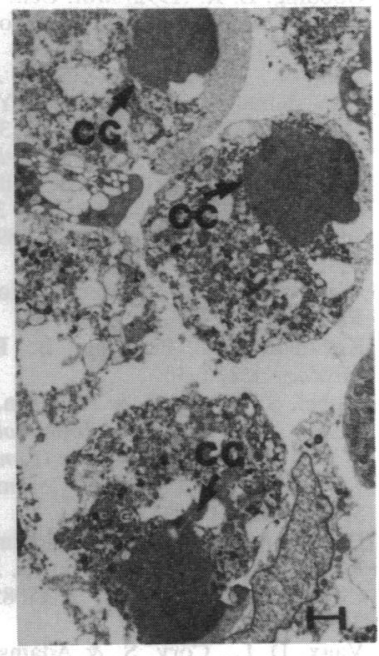

FIg. 4. Transformed cell lines that lack the E1B 19-kDa protein die by apoptosis. (Upper) Induction of DNA fragmentation in $\mathrm{E} 1 \mathrm{~A}+\mathrm{E} 1 \mathrm{~B} 55-\mathrm{kDa}$ but not E1A+E1B or E1A+E1B 19-kDa transformed cell lines. The indicated transformed BRK cell lines were grown as described in the legend to Fig. 3 and at day 8, 3 days after reaching maximum density when viability of the E1A+E1B 55-kDa transformants was low, the integrity of the chromosomal DNA was determined (21). Marker, size markers $\left(\times 10^{-3}\right.$ base pairs). (Lower) Ultrastructural appearance of E1A+E1B 55-kDa cell line $55 \mathrm{C}$ following induction of cell death by serum deprivation. (Left) Cells at low density maintained in high serum $(10 \%)(\times 2500)$. (Right) Cells at low density maintained in low serum $(0.1 \%)$ for $24 \mathrm{hr} .(\times 1500$.) Nuclei with condensed chromatin (CC) are indicated. $(\mathrm{Bar}=1 \mu \mathrm{m}$.)

function is less optimal in kidney epithelial cells than lymphoid cells. Alternatively, Bcl-2 may substitute for only a portion of E1B 19-kDa protein effects in blocking apoptosis.

Four stable transformed cell lines were derived from E1A and $\mathrm{Bcl}-2$ cooperation assays and the level of expression of the human Bcl-2 protein was determined by Western blotting with human specific Bcl-2-specific monoclonal antibodies $6 \mathrm{C} 8$ and $\mathrm{Bcl}-2 / 100$. These antibodies do not crossreact with the endogenous rat protein and consequently no $\mathrm{Bcl}-2$ protein product is demonstrable in the E1A+E1B transformed rat lines (Fig. 5, lane 5). In contrast, all four E1A+SFFV Bcl-2
Cooperation Between E1A and Bcl-2
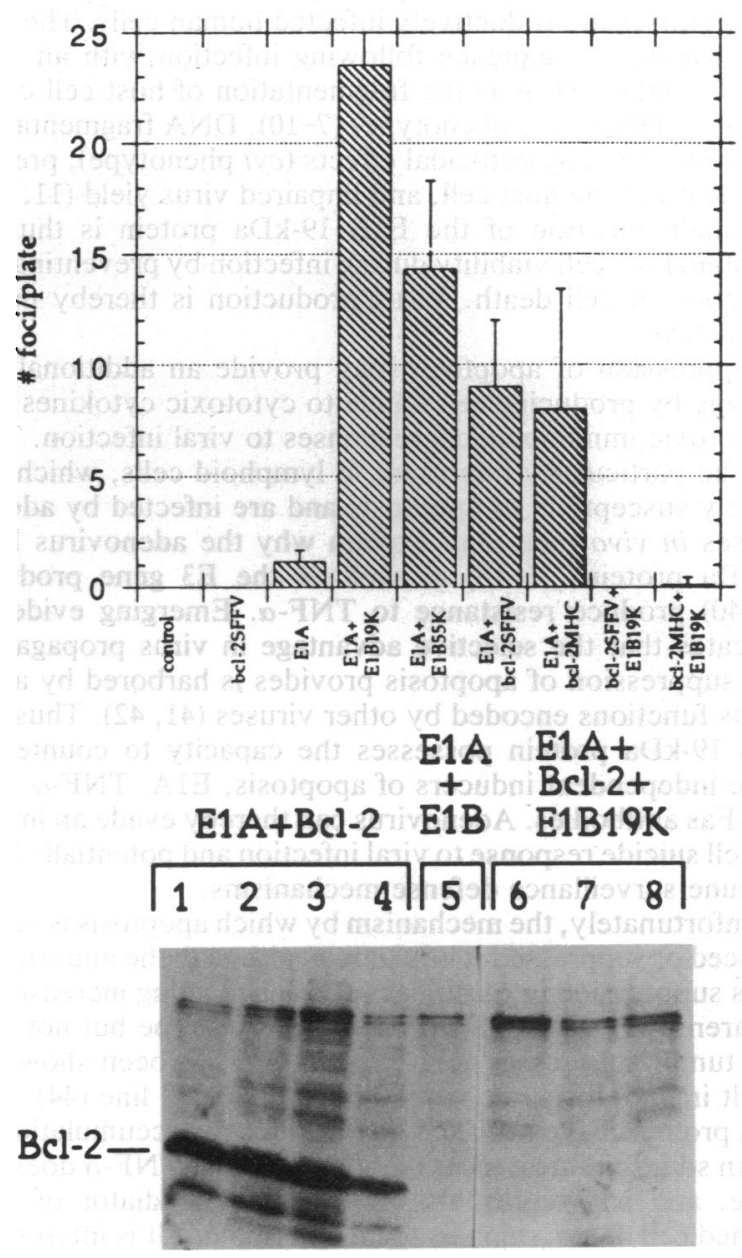

FIG. 5. Cooperation between Bcl-2 and E1A. (Upper) Primary BRK cells were transfected with the indicated plasmid DNAs and the frequency of focus formation was determined after 28 days in a standard focus assay. Growth to a focus diameter $\geq 5 \mathrm{~mm}$ was used as a criterion for focus formation. The human Bcl-2 plasmid expression vectors Bcl-2SFFV and Bcl-2MHC have been described (23). A compilation of data from three independent experiments is shown. (Lower) Western blot of stable BRK cell lines derived from a standard focus assay probed with a monoclonal antibody directed against human $\mathrm{Bcl}-2$ (6C8). Similar results were obtained with the Bcl-2/100 monoclonal antibody (data not shown). For each line equal amounts of protein $(20 \mu \mathrm{g})$ were analyzed. Lanes $1-4$, four independent lines derived from transfection with the E1A and Bcl-2SFFV plasmids: lane 5, E1A+E1B transformed cell line 4D (ref. 2), which lacks the human $\mathrm{Bcl}-2$ gene; lanes $6-8$, three independent lines derived from transfection of E1A, Bcl-2SFFV, and CMV19K expression vectors. The position of the Bcl-2 protein is indicated.

transformants expressed the human Bcl-2 protein (Fig. 5, lanes 1-4). The level of expression of Bcl-2 in these transformed rat kidney lines was comparable to that in a human lymphoid line (Jurkat) where Bcl-2 is highly expressed (data not shown). Transfection of the E1B 19-kDa expression vector with E1A and Bcl-2 appears to have removed the selective pressure for Bcl-2 expression in the focus assay, and these stable transformants did not display detectable human Bcl-2 protein (Fig. 5, lanes 6-8). Therefore, although Bcl-2 can cooperate with E1A in a transformation assay it does not appear to be as effective as the E1B 19-kDa protein.

\section{DISCUSSION}

Induction of apoptosis by E1A and its inhibition by the E1B 19-kDa protein offer an explanation not only for the response 
of primary rodent cells to transformation reported here but also for phenotypes displayed by E1A and E1B mutant adenoviruses in productively infected human cells. The major, striking consequence following infection with an E1B $19-\mathrm{kDa}$ mutant virus is the fragmentation of host cell chromosomal DNA (deg phenotype) (7-10). DNA fragmentation is accompanied by cytocidal effects (cyt phenotype), premature death of the host cell, and impaired virus yield $(11,12)$. The main function of the E1B $19-\mathrm{kDa}$ protein is thus to maintain host cell viability during infection by preventing the induction of cell death. Virus production is thereby maximized (15).

Suppression of apoptosis may provide an additional advantage by producing resistance to cytotoxic cytokines and other toxic immunological responses to viral infection. This may be particularly important in lymphoid cells, which are acutely susceptible to apoptosis and are infected by adenoviruses in vivo, and may explain why the adenovirus E1B $19-\mathrm{kDa}$ protein $(16-18)$ as well as the E3 gene products (37-40) produce resistance to TNF- $\alpha$. Emerging evidence indicates that the selective advantage in virus propagation that suppression of apoptosis provides is harbored by analogous functions encoded by other viruses $(41,42)$. Thus the E1B $19-\mathrm{kDa}$ protein possesses the capacity to counteract three independent inducers of apoptosis, E1A, TNF- $\alpha$, and anti-Fas antibodies. Adenovirus can thereby evade an intrinsic cell suicide response to viral infection and potentially host immune surveillance defense mechanisms.

Unfortunately, the mechanism by which apoptosis is either induced or suppressed is not known, although the importance of its suppression in carcinogenesis is becoming increasingly apparent (43). Overexpression of the wild-type but not mutant tumor suppressor gene product $\mathrm{p} 53$ has been shown to result in apoptosis in a myeloid leukemic cell line (44). The E1A proteins have been shown to induce the accumulation of p53 in some circumstances (45), but whether TNF- $\alpha$ does the same, and p53 represents the universal mediator of programed cell death, remains to be determined. It is interesting to note that the E1B 55-kDa protein that binds to and presumably sequesters p53 (6) can partially overcome apoptosis triggered by E1A. This suggests that disposing of p53 is not completely sufficient to block apoptosis and a second function provided by the E1B 19-kDa protein is required. Alternatively, p53 sequestration by the E1B 55-kDa protein may not be complete, which suggests that E1B 19-kDa protein may contribute to p53 elimination.

Another mechanism for apoptosis suppression involves the Bcl-2 protooncogene. Overexpression of $\mathrm{Bcl}-2$ will block apoptosis, thereby extending the lifespan of $B$ cells and promoting transformation $(23,46)$. We report here that Bcl-2 can complement E1A in cooperation assays in an analogous fashion to the E1B gene. Latent membrane protein 1 (LMP-1) of Epstein-Barr virus can facilitate viral latency and oncogenic transformation by elevating levels of $\mathrm{Bcl}-2$ to inhibit apoptosis (42). The E1B 19-kDa protein apparently encodes a similar function that confers an advantage to adenovirus survival and facilitates oncogenic transformation. The mechanism utilized by the E1B 19-kDa protein differs, however, from LMP-1, as levels of Bcl-2 protein are not altered by E1B 19-kDa expression in human cells, which are resistant to apoptosis (unpublished observations). Initiation of a chain of events may be required to induce apoptosis, the individual components of which are potentially susceptible to intervention by viral gene products. Apoptosis may represent a cell suicide response to deregulation of cell growth that is targeted for inactivation by transforming proteins of DNA tumor viruses.
We thank Raj Patel and David Birk for assistance with the electron microscopy and photography. This work has been supported by the New Jersey Commission on Science and Technology, Public Health Service grants (CA13106 and CA53370 to E.W.), and a training grant in biotechnology from the National Institutes of Health (GM08339-02 to M.D.)

1. Shenk, T. \& Flint, J. (1991) Adv. Cancer Res. 57, 47-85.

2. White, E. \& Cipriani, R. (1990) Mol. Cell. Biol. 10, 120-130.

3. Barker, D. D. \& Berk, A. J. (1987) Virology 156, 107-131.

4. Bernards, R., deLeeuw, M. G. W., Houweling, A. \& van der Eb, A. J. (1986) Virology 150, 126-139.

5. McLorie, W., McGlade, C. J., Takayesu, D. \& Branton, P. E. (1991) J. Gen. Virol. 72, 1467-1471.

6. Sarnow, P., Shih Ho, Y., Williams, J. \& Levine, A. J. (1982) Cell 28, 387-394.

7. White, E., Grodzick ir, T. \& Stillman, B. (1984) J. Virol. 52, 410-419.

8. Pilder, S., Logan, J. \& Shenk, T. (1984) J. Virol 52, 664-671.

9. Takemori, N., Riggs, J. L. \& Aldrich, C. (1968) Virology 36, 575-586.

10. Takemori, N., Cladaras, C., Bhat, B., Conley, A. J. \& Wold, W. S. M. (1984) J. Virol. 52, 793-805.

11. Subramanian, T., Kuppuswamy, M., Gysbers, J., Mak, S. \& Chinnadurai, G. (1984) J. Biol. Chem. 259, 11777-11783.

12. White, E., Faha, B. \& Stillman, B. (1986) Mol. Cell. Biol. 6, 3763-3773.

13. White, E. \& Stillman, B. (1987) J. Virol. 61, 426-435.

14. White, E., Cipriani, R., Sabbatini, P. \& Denton, A. (1991) J. Virol. 65, 2968-2978.

15. White, E., Denton, A. \& Stillman, B. (1988) J. Virol. 62, 3445-3454.

16. Gooding, L. R., Aquino, L., Duerksen-Hughes, P. J., Day, D., Horton, T. M., Yei, S. \& Wold, W. S. M. (1991) J. Virol. 65, 3083-3094.

17. Hashimoto, S., Ishii, A. \& Yonehara, S. (1991) Int. Immunol. 3, 343-351.

18. White, E., Sabbatini, P., Debbas, M., Wold, W. S. M., Kusher, D. \& Gooding, L. R. (1992) Mol. Cell. Biol., 12, 2570-2580.

19. Laster, M., Good, J. G. \& Gooding, L. R. (1988) J. Immunol. 141, 2629-2634.

20. Itoh, N., Yonehara, S., Ishii, A., Yonehara, M., Mizusshima, S., Sameshima, M., Hase, A., Seto, Y. \& Negata, S. (1991) Cell 66, 233-243. 21. Hirt, B. (1967) J. Mol. Biol. 26, 365-369.

22. Jones, N. \& Shenk, T. (1979) Cell 17, 683-689.

23. Hockenbery, D., Nunez, G., Milliman, C., Schreiber, R. D. \& Korsmeyer, S. (1990) Nature (London) 348, 334-336.

24. White, E. \& Cipriani, R. (1989) Proc. Natl. Acad. Sci. USA 86, 9886-9890.

25. van den Elsen, P., de Pater, S., Houweling, A. \& van der Eb, A. J. (1983) Virology 128, 377-390.

26. Kaczmarek, L., Ferguson, B., Rosenberg, M. \& Baserga, R. (1986) Virology 152, 1-10.

27. Stabel, S., Argos, P. \& Philipson, L. (1985) EMBO J. 4, 2329-2336.

28. Cohen, J. J. (1991) Adv. Immunol. 50, 55-85.

29. Wyllie, A. H. (1980) Nature (London) 284, 555-556.

30. Tsujimoto, Y., Gorham, J., Cossman, J., Jaffe, E. \& Croce, C. M. (1985) Science 229, 1390-1393.

31. Bakhashi, A., Jensen, J. P., Goldman, P., Wright, J. J., McBride, O. W., Epstein, A. L. \& Korsmeyer, S. J. (1985) Cell 41, 889-906.

32. Cleary, M. L. \& Sklar, J. (1985) Proc. Natl. Acad. Sci. USA 82, 7439-7443.

33. Vaux, D. L., Cory, S. \& Adams, T. M. (1988) Nature (London) 335, $440-442$.

34. Nunez, G., London, L., Hockenbery, D., Alexander, M., McKearn, J. P. \& Korsmeyer, S. J. (1990) J. Immunol. 144, 3602-3610.

35. McDonnell, T. J. \& Korsmeyer, S. J. (1991) Nature (London) 349, 254-256.

36. Sentman, C. L., Shutter, J. R., Hockenbery, D., Kanagawa, O. \& Korsmeyer, S. J. (1991) Cell 67, 879-888.

37. Ames, R. S., Holskin, B., Mitcho, M., Shalloway, D. \& Chen, M.-J. (1990) J. Virol. 64, 4115-4122.

38. Chen, M.-J., Holskin, B., Strickler, J., Gorniak, J., Clark, M. A., Johnson, P. J., Mitcho, M. \& Shalloway, D. (1987) Nature (London) 330, 581-583.

39. Duerksen-Hughes, P. J., Hermiston, T. W., Wold, W. S. M. \& Gooding, L. R. (1991) J. Virol. 65, 1236-1244.

40. Duerksen-Hughes, P., Wold, W. S. M. \& Gooding, L. R. (1989) J. Immunol. 143, 4193-4200.

41. Clem, R. J., Fechheimer, M. \& Miller, L. K. (1991) Science 254, 1388-1391.

42. Henderson, S., Rowe, M., Gregory, C., Croom-Carter, D., Wang, F., Longnecker, R., Keiff, E. \& Rickinson, A. (1991) Cell 65, 1107-1115.

43. Williams, G. (1991) Cell 65, 1097-1098.

44. Yonish-Rouach, E., Resnitzky, D., Lotem, J., Sachs, L., Kimchi, A. \& Oren, M. (1991) Nature (London) 352, 345-347.

45. Braithwaite, A. W., Nelson, C., Skulimowski, A., McGovern, J., Pigot, D. \& Jenkins, J. (1990) Virology 177, 595-605.

46. Nunez, G., Hockenbery, D., McDonnell, T. J., Sorensen, C. M. \& Korsmeyer, S. (1991) Nature (London) 353, 71-73. 